\title{
Biometrics was no match for hair-raising tricks
}

\author{
People have been fooling the latest thing in security for a very long time.
}

Sir - Although biometric technology is believed to be a product of the hi-tech era, it is not, in fact, our generation's invention. People were using biometric technology long before the word 'biometric' was coined (see Nature 418, 583; 2002; and 420, 15; 2002). Not only that, but attempts to fool it were as common in ancient times as they are today.

The oldest written testimony of identity theft we can find dates back to biblical times, when Jacob fraudulently used the identity of his twin brother Esau to benefit from their father's blessing. Genesis describes a combination of hand scan and voice recognition that Isaac used to attempt to verify his son's identity, without knowing that the smooth-skinned Jacob had wrapped his hands in kidskin: "And Jacob went near unto Isaac his father; and he felt him, and said, 'The voice is Jacob's voice, but the hands are the hands of Esau'. And he recognized him not, because his hands were hairy, as his brother Esau's hands." The false acceptance which resulted from this very inaccurate biometric test had historical consequences of unmatched proportions.

In Greek mythology, too, we are likely to find surprises. A primitive tactile sensor used by the one-eyed Cyclops after Odysseus and colleagues had destroyed his monocular face-recognition system and which they evaded by hiding under his sheep — was actually the first biometric lock, operated more than two millennia before James Bond conquered the screen with his hi-tech gadgets.

Turning the dusty pages of the classics, we discover a wide spectrum of biometric technologies, from voice recognition triumphantly deceived by Dante's Gianni Schicchi, who impersonated a dead man to change a will in his own favour - to the unbeatable feature-matching facerecognition algorithm implemented by the fairy-tale heroine Little Red Riding Hood, who was unconvinced by a wolf disguised as her grandmother.

Scientists would be envious to find out that many state-of-the-art approaches in biometrics are merely a rediscovery: to quote Ecclesiastes, "nothing is new under the sun".

Michael M. Bronstein, Alexander M. Bronstein

Department of Electrical Engineering, Technion Israel Institute of Technology, Haifa 32000, Israel

\section{Scientific misconduct: the state's role has limits}

Sir - The Association of American Medical Colleges (AAMC) has long fostered research integrity, developed ethical codes for scientific societies, promulgated guidelines for inquiries into allegations of scientific misconduct, issued policies and recommendations for dealing with financial conflicts of interest in clinical research, and, most recently, collaborated with the Office of Research Integrity (ORI) in educational efforts and workshops on the responsible conduct of research. The AAMC has long recognized that misconduct breaches the social contract underpinning academic science and undermines a scientific establishment that sets the standard of international excellence. Contrary to your assertion, the AAMC strongly supports ethics training for graduate students and postdoctoral research fellows.

In his annual address to academic leaders and the public, the AAMC president, Jordan Cohen, stated "either we are trustworthy and deserve the privilege of self-regulation, or we are suspect and warrant the close scrutiny of government." We are proud of our record, which speaks for itself.

Your Opinion article (Nature 420, 253; 2002) mischaracterizes the opposition expressed by the AAMC and the Federation of American Societies for Experimental Biology (FASEB) to the ORI's proposed data-collection instrument. Our objections focus on two critical elements: first, the likelihood that the survey would result in unusable, invalid and easily misinterpreted 'data' based on subjective criteria and imprecise measures. One example of this is mentioned in your editorial — asking for instances where a researcher observed a colleague "citing an article they had not read firsthand". Our second objection is to the ORI's inexplicable defiance of the settled federal definition of scientific misconduct, which can lead only to confusion.

The crux of the issue, which you fail to comprehend, is that the federal definition of 'scientific misconduct' is a marker for the proper role of government in overseeing the conduct of federally funded academic research. On this matter, the US scientific community has consistently spoken with a single voice in arguing that this role be circumscribed and focused on transgressions that are reasonably unambiguous and are unacceptable across all scientific and scholarly disciplines.

This unanimity does not imply, however, that the boundaries of unethical scientific and professional behaviour should be so circumscribed - quite the contrary. It is not the role of the federal government to define or prescribe those ethical boundaries. Rather, it is the obligation of academia and scientific societies, and it is to stimulate and assist our member institutions to meet that obligation that the AAMC has been so actively and demonstrably engaged for so long.

Perhaps Nature believes that science needs a federally sanctioned 'high church' as the final arbiter of scientific morals, ethics and integrity. The AAMC, and, we believe, all of US science, profoundly disagrees. David Korn

Senior Vice President, AAMC, 2450 North Street, Northwest Washington, DC 20037, USA

\section{Scientific misconduct: ORI survey is flawed}

Sir - The Federation of American Societies for Experimental Biology (FASEB) abhors misconduct in research and has repeatedly emphasized the need for clear, unambiguous and consistent definitions of misconduct. The accusations you make in Opinion (Nature 420, 253; 2002) misrepresent our criticism of the US Office of Research Integrity's (ORI's) flawed survey questionnaire.

We do not object to data collection on misconduct. Institutions currently provide this information to the ORI on an annual basis. Our opinion is that the proposed ORI survey has serious deficiencies and will not produce useful data.

The ORI itself stated that previous attempts to measure misconduct were unsuccessful because they strayed from the federal misconduct definition. The issues of fabrication, falsification and plagiarism are too important to be confused with other questions, many of which involve legitimate differences of opinion. The survey's vague questions, such as asking respondents how many times they have observed colleagues "failing to cite references that contradict their current research" or "refusing to give peers reasonable access to unique research materials", will give a misleading impression of how research is done. Although it is easy to circle a number, there may be wide variation in the ethical status of the examples being reported by individuals. Simple summaries of complex issues will lump legitimate actions together 
with malevolent cases.

Your editorial fails to inform readers that the ORI is not merely proposing to measure "other" misbehaviour, but also "perceived" misbehaviour, which is key to our objection. The survey will not generate a measure of misconduct, but a recording of hearsay or innuendo. For example, one question asks whether the respondent knows of colleagues "citing an article they had not read firsthand". This orwellian approach, which encourages scientists to spy on each other's reading habits, will not lead to clarification of the ethical status of biomedical research.

You imply that there was a conspiracy behind the creation of the current definition of research misconduct. This is incorrect. The record clearly shows that there was an extended debate and many opportunities for public comment. We have supported efforts to improve education in research ethics, as I stated publicly in remarks at the 10 October Institute of Medicine town meeting. FASEB's August 2000 letter commenting on the draft PHS Policy for Instruction in the Responsible Conduct of Research states: "Students and trainees must have instruction in the responsible conduct of research. But the extension of this requirement to 'all staff' including subcontractors and consultants will result in an enormous involvement of time and resources." Our policy statements show our consistent commitment to the responsible conduct of research. There is no basis for implying that our position condones, supports or protects unethical behaviour. Steven L. Teitelbaum

President, FASEB, Dept of Pathology and Immunology, Washington University School of Medicine, MS 90-31-649, 216 Kingshighway, St Louis, Missouri 63110, USA

\section{Sounding the alarm on underwater noise}

\section{Sir - Your News feature on fisheries} management (Nature 419, 662; 2002) raises the important point of considering each fishery in the context of its larger ecological context, although you identify overfishing as the root cause of fisheries depletion. This perspective puts the onus of fisheries health exclusively on the fishing industry.

Agricultural runoff, the pollution and disappearance of estuarine and wetland nurseries and, increasingly, anthropogenic 'noise' are all compromising ocean health

— to such a degree that fisheries population crashes might occur even without commercial overharvesting.

Only recently has anthropogenic noise been acknowledged as a threat to marine ecology, as evidenced by whale and dolphin strandings caused by military sonar (Nature 415, 106; 2002). Noises caused by shipping, underwater seismic exploration, sonar, underwater telemetry and military exercises have all increased dramatically over the past decade. Many fish rely on acoustical perception to hunt, school, evade predators and find mates. Cluttering their acoustical niches with noise affects their survival prospects. Michael Stocker

Seaflow.org, PO Box 559, Lagunitas,

California 94938, USA

\section{Why astronomy is the star of the news show}

Sir - Space science news is good news, according to the Pew Research Center for the People and the Press, which tracks the "most closely followed" news stories in the United States (http://people-press.org/ reports). From 1986 to 1999, the Pew study found 689 such items, 39 of them related to science, medicine and the weather. To a striking degree, these 39 stories had disturbing news to tell — earthquakes or other natural calamities, nuclear power, AIDS or controversies over cloning. Virtually every 'good news' science story was about space science, for example reports of the Hubble Space Telescope (1990) and Mars Pathfinder (1997) missions. The only other scientific subject reported in a positive light was Viagra.

Perhaps this 'good news' feature of astronomy and space science helps to explain their broad popularity. A recent NSF survey reports that $74 \%$ of adults in 1999 were interested in space exploration, and many people (57\% in 1999) agreed that it is worth its costs (see "Public Attitudes Towards Space Science", by H.A.S., in Space Science Reviews Vol. 102, 3-4, Kluwer, 2002.)

Politicians mindful of public morale might want to note this phenomenon, as might budget-conscious managers who seem to suspect that astronomy and space science do not give adequate value-fordollar (and/or are badly managed). The current US administration, for example, and its Office of Management and Budget (OMB), in an effort to remedy these perceived faults, are "measuring the performance" of government-supported research so that "spending on fundamental research will be judged by formal 'performance criteria'" (see Nature 415, 466-467; 2002). In the spirit of "improving management", the OMB first proposed to move the National Science Foundation's astronomy funding to other agencies with little clear reason, support or success
— and subsequently proposed the opposite: moving some astronomy (and other research) funding into the foundation (see Nature 414, 680; 2002).

How does one calculate value-fordollar in a discipline such as astronomy, whose primary product is knowledge? As succinctly (but unhelpfully) put by one astronomer, Nicholas Copernicus, the aim of a scientist is "to seek the truth in all things". But without a sense of the worth of research accomplishments, how can those formal performance criteria for measuring and managing be identified, and then seriously and sensibly applied? Surely one lesson of the collapse of the telecommunications giant Enron is that 'measuring' and 'managing' are techniques that are themselves subject to error, incompetence, inefficiency and worse.

This is where the good-news aspect of astronomy comes in. Gerald Holton and Gerhart Sonnert (Issues in Science and Technology, 61-65; Fall 1999) have proposed a model in which basic research falls into three categories whose respective goals are knowledge, applied knowledge and (after Thomas Jefferson) knowledge with the realization that something practical might ensue. John F. Kennedy expressed a fourth goal: the public spirit. As he put it when justifying the Apollo programme: "We choose to go to the Moon in this decade, and do the other things, not because they are easy, but because they are hard... No single space project in this period will be more impressive to mankind." In the words of the current NASA Administrator, Sean O'Keefe, NASA's “mandate is to pioneer the future... NASA's work inspires Americans and unites people."

Public spirit and public interest, though intangible, are reflected in the media. New planets, new insights into the creation of the Universe, and other cosmic discoveries regularly merit upbeat front-page coverage because the pictures are inspirational, the stories are relatively easy to understand, the adventures are exciting, the discoveries are often meaningful, and the successes make us happy to be alive. Other science research disciplines (and their public outreach programmes) might also benefit from performance criteria that include a mediabased appraisal of public attitudes. At least for astronomy the news is good accountants, please add 10 points. Howard A. Smith

Harvard-Smithsonian Center for Astrophysics, 60 Garden Street, Cambridge,

Massachusetts 02138, USA

\section{correspondence}

contributions to correspondence may be submitted to corres@nature.com. They should be no longer than 500 words, and ideally shorter. 